\title{
Crystallographic Studies in Cultural Heritage: Solid State Behaviour of Inorganic Pigments
}

\author{
Ulrich Baisch ${ }^{1,2, *} \mathbb{0}$, Marie Camilleri ${ }^{1} \oplus$, Duncan Micallef ${ }^{1}$, Timo Rhauderwiek ${ }^{3}$, \\ Norbert Stock $^{3}$, Rebecca Spiteri ${ }^{1}$ (D) and Liana Vella-Zarb ${ }^{1,2, *(D)}$ \\ 1 Department of Chemistry, University of Malta, MSD 2080 Msida, Malta; \\ marie.m.camilleri.13@um.edu.mt (M.C.); duncan.micallef.11@um.edu.mt (D.M.); \\ rebecca.spiteri.95@gmail.com (R.S.) \\ 2 School of Natural Sciences, Bedson Building, Newcastle University, Newcastle-upon-Tyne NE1 7RU, UK \\ 3 Institut für Anorganische Chemie, Christian-Albrechts-Universität zu Kiel, Max-Eyth-Straße 2, D-24118 Kiel, \\ Germany; timo.rhauderwiek@gmail.com (T.R.); stock@ac.uni-kiel.de (N.S.) \\ * Correspondence: ulrich.baisch@um.edu.mt (U.B.); liana.vella-zarb@um.edu.mt (L.V.-Z.); \\ Tel.: +356-2340-3425 (U.B.); +356-2340-3691 (L.V.-Z.)
}

Received: 26 January 2019; Accepted: 13 March 2019; Published: 20 March 2019

\begin{abstract}
Most inorganic pigments generally consist of the colouring agents such as hematite (red) or glauconite (green) together with white pigments, including alumosilicates and calcium compounds. This usually leads to a wide colour range dependent on the exact percentage of the colouring agent in the solid mixture. Some inorganic pigments have been in use for thousands of years due to their easy availability and desirable attributes: ochres have been in use since prehistoric times to produce cave and rock paintings, and are still used to this day; terra verde (green earth) first made its appearance in decorations and frescos in the first century B.C. Whether these pigments are used in frescos, cave ornaments or paintings, shortcomings in their particular hue, transparency or fading character very often inspire research towards a better understanding of these physical characteristics. We present a study in which crystal engineering was applied in an attempt to tackle such problems. The solubility of Venetian red ochre and its solid state behaviour at higher temperatures were investigated and compared with similar studies on terra verde. Hot stage microscopy showed that, although the pigment retained its red colour upon heating, some crystallites lost transparency, indicating a phase change. The actual colouring agents hematite and goethite in Venetian red ochre are insoluble in most solvents and solvent mixtures. However, the solvent was found to have a significant effect on the undissolved pigment and other components. The pigment examined in this study was a mixture of microcrystalline powders with smaller quantities of larger crystallites thought to be gypsum. Multi-elemental analysis by X-ray fluorescence spectroscopy showed the most abundant elements to be sulphur, calcium, iron, magnesium, silicon and aluminium. Fourier-Transform Infrared (FTIR) spectroscopy indicated the presence of metal oxides, metal carbonates and alumosilicates. Powder X-ray diffraction experiments helped to identify and quantify the proportions of hematite and goethite in four different pigments.
\end{abstract}

Keywords: pigments; inorganic; ochre; terra verde; crystallography; crystal engineering

\section{Introduction}

Amongst the most used and well-known natural earth pigments, there are terra verde (Green Earth) and red ochre. This is not only due to their natural abundance, but also because of their special transparency and wide range of colours, comprising several shades of green, yellow, orange, red and violet. They have been used as artistic pigments for thousands of years. Due to their wide range of 
colours, easy availability and desirable attributes, the use of ochres and terra verde as pigments is global [1]. Red ochres have been used to produce cave and rock paintings [2] since prehistoric times, and they were also widely used in burial rituals [3]. As technology gradually developed, iron oxides gained use as colourants for ceramic, pottery and mural decorations [4]. During the late Bronze Age and early Iron Age periods, red ochre was used in funeral vessels to obtain bright red colours [1]. Over the centuries, red ochre has remained prominent in art and decoration, with its continued use in frescos and paintings, and, during the 19th century, ochres were transformed into commercially-viable pigments [1].

Terra verde has been in use by artists for centuries. Its widespread use may be attributed, in part, to the fact that the pigment can be found in Europe, different regions in America, India and eastern Africa [5]. With its first reported use dating back to the first century B.C. [6], terra verde has been identified in artefacts ranging from pot decorations to frescos, such as in decorations on pottery found in a shop in Pompeii and the frescos found in the bath of Titus in Rome and the temple of Venus in Pompeii [6,7]. The pigment's most common use was during the High Renaissance, when terra verde was applied as an underpainting for flesh tones and shadow colours on the skin. It was used for this purpose mainly since green and pink (skin colour) are complementary $[5,8,9]$. This painting technique can be seen in the uncompleted work attributed to Michelangelo Buonarroti, referred to as Madonna and Child with St. John and Angels [5]. In most of the above cases, the pigment was locally sourced [6,9], making it easily available.

The colour in both pigments, red ochre and terra verde, arises due to the presence of minerals: (a) iron-containing minerals in red ochre, namely hematite and goethite; and (b) magnesium, aluminium, iron and titanium containing aluminosilicates minerals (glauconite and celadonite) in terra verde. Hematite $\left(\alpha-\mathrm{Fe}_{2} \mathrm{O}_{3}\right)$ gives ochres a red colour, whereas goethite $(\alpha-\mathrm{FeOOH})$ gives ochres a yellow colour. Apart from hematite and goethite, ochres generally contain other minerals, which are classified as white pigments, including aluminosilicates, quartz and calcium compounds. The varying proportions of hematite and goethite determine the colour of the ochre [10,11]. Due to this, ochres exist in several hues of yellow and red, together with other shades which fall in between. The colour of ochres and their chemical composition have been linked together quantitatively, providing an explanation to the large colour variation. This was found to arise due to the presence of the $\mathrm{Fe}^{3+}$ ion, and the charge transfer between this ion and its ligands, $\mathrm{O}^{2-}$ or $\mathrm{OH}^{-}$, in hematite and goethite respectively [10].

The aim of the present study was to explore the materials properties of a variety of red and yellow ochres (Venetian red ochre, Italian yellow ochre, Pozzuoli red and lemon ochre) with varying temperature and in the presence of different solvents, in line with the crystal engineering approach. The results were compared with a previously published study of terra verde using Verona Green Earth pigment, which also consisted of a mixture of glauconite and celadonite. A solubility study was carried out using five different solvents and four solvent mixtures to determine the effect of solvents on the mainly undissolved pigment. Several techniques were employed to characterise Venetian red ochre, including hot-stage microscopy, X-Ray Fluorescence spectroscopy (XRF), Fourier-Transform Infrared (FT-IR) spectroscopy, UV-Vis spectroscopy and powder X-ray diffraction (PXRD).

\section{Materials and Methods}

\subsection{Materials}

The pigments used for this study were Venetian red ochre, Pozzuoli red ochre, Italian yellow earth, Lemon ochre and Verona terra verde, commercial pigments supplied by Rublev ${ }^{\circledR}$ colours. The potassium bromide used for FT-IR spectroscopy was of FT-IR grade (Sigma Aldrich, St. Louis, MO, USA, $\geq 99 \%$ trace metal basis). The solvents used for the solubility study were ethanol (Sigma Aldrich 96\%), dimethyl sulfoxide (Sigma Aldrich 99\%), methanol (Sigma Aldrich 99\%) and acetone (Biosolve, reaction grade). Solvents and materials were used "as bought" without further purification. 


\subsection{Instrumentation}

Hot-Stage Microscopy. Observations and production of micrographs were carried out using a Leica Z16 APO microscope (Leica Microsystems, Wetzlar, Germany), equipped with polariser and QImaging QICAM Fast1394 digital camera (Surrey, BC, Canada), using Q-capture Pro 7 software. A Linkam TMS600 hot stage apparatus (Linkam, Tadworth, Surrey, UK), using Linksys 32 software, was attached to the microscope. A typical temperature profile involved initially raising the temperature from $25^{\circ} \mathrm{C}$ to $580{ }^{\circ} \mathrm{C}$ at a rate of $10^{\circ} \mathrm{C} \mathrm{min}^{-1}$, and then cooling down to $25^{\circ} \mathrm{C}$ at a rate of $20^{\circ} \mathrm{C} \mathrm{min}^{-1}$.

$X$-Ray Fluorescence. Multi-element analysis was carried out on a Bruker S2 Ranger energy dispersive X-ray fluorescence spectrometer (Bruker, Madison WI, USA), fitted with a Varian VF50 $X$-ray tube. The sample was prepared for X-ray fluorescence using a sample cup and Mylar thin-film. Measurements were taken in helium atmosphere in four regions, namely $50 \mathrm{kV} \mathrm{Cu}(250.0 \mu), 40 \mathrm{kV} \mathrm{Al}$ $(500.0 \mu), 20 \mathrm{kV}$ and $10 \mathrm{kV}$, with the measurement time per region being $100 \mathrm{~s}$. Evaluation was done in three ranges: $50 \mathrm{kV} \mathrm{Cu}(250.0 \mu), 40 \mathrm{kV} \mathrm{Al}(500.0 \mu)$ and $20 \mathrm{kV}$.

FTIR Spectroscopy. FT-IR transmission spectra were recorded on a Shimadzu IRAffinity-1 FT-IR spectrophotometer (Shimadzu, Kyoto, Japan), using IR solution software. The spectra were acquired with 30 scans on a range from 400 to $4000 \mathrm{~cm}^{-1}$, and a spectral resolution of $4 \mathrm{~cm}^{-1}$. The spectra were recorded using the pressed pellet method, in which a small amount of ground pigment was mixed with approximately 100 times its weight of powdered potassium bromide. The powder was then put in an Apollo Scientific $13 \mathrm{~mm}$ die set and pressed under 10 tonnes for $2 \mathrm{~min}$ using a 30 tonne press from Research and Industrial Instruments Company England, forming a pellet. The spectrum of a potassium bromide pellet with no pigment was used as background.

Powder X-Ray Diffraction. Powder X-ray diffraction data were collected on a STOE Stadi P diffractometer (STOE \& Cie, Darmstadt, Germany), equipped with a MYTHEN detector or a stationary position sensitive detector, using either Mo or $\mathrm{Cu} \mathrm{K}_{\alpha}$ radiation $(40 \mathrm{kV}, 30 \mathrm{~mA})$ and a curved Germanium (111) monochromator. Data collections were carried out in the range $0^{\circ}<2 \theta<45^{\circ}$ with a step size of $0.015^{\circ}$. Topas 6.1 [12] was utilised for Rietveld refinement.

\subsection{Experimental}

Solubility and Effect of Solvents on Venetian Red Ochre. The solubility of some of the components in Venetian red ochre was investigated using various solvents (water, ethanol, methanol, acetone and dimethylsulfoxide) and solvent:water mixtures in a 1:1 ratio. Twenty-five milligrams of ground pigment and $20 \mathrm{~mL}$ of each solvent or solvent mixture were used. The pigment-solvent mixtures were stirred at $250 \mathrm{rpm}$ at $45^{\circ} \mathrm{C}$ for $1 \mathrm{~h}$. They were subsequently filtered through grade 5 filter paper and the solutions obtained together with the undissolved pigment were retained for further analysis. The solutions, consisting of the solvent and any dissolved chemical species, were analysed using UV-Vis spectroscopy. The undissolved pigment portions in each sample were dried for $1 \mathrm{~h}$ at $80^{\circ} \mathrm{C}$, and were subsequently analysed by FT-IR spectroscopy and hot stage microscopy. For the latter, the temperature was raised from $25^{\circ} \mathrm{C}$ to $580{ }^{\circ} \mathrm{C}$ at a rate of $15^{\circ} \mathrm{C} \mathrm{min}-1$, and then cooled down to $30{ }^{\circ} \mathrm{C}$ at a rate of $50{ }^{\circ} \mathrm{C} \mathrm{min}^{-1}$.

\section{Results and Discussion}

\subsection{Solid State Behaviour of Venetian Red Ochre at High Temperatures}

Hot stage microscopy was used to determine the effect of temperature on Venetian red ochre. Upon heating, no colour change was observed. The larger crystallites, however, lost transparency upon heating, indicating a phase change or decomposition (Figure 1). Venetian red ochre was also ground together with a few drops of deionised water and analysed using hot stage microscopy. Again, no colour change was observed, but a slight movement of the solid was seen between 100 and $125^{\circ} \mathrm{C}$, indicating loss of water. This behaviour is in accordance with results of variable temperature experiments on Verona terra verde [13]. In addition, on reaching the temperature of $125^{\circ} \mathrm{C}$, a loss of 
crystallinity was observed followed by a colour change from green to a yellow-brown colour. This was likely due to the oxidation from $\mathrm{Fe}^{2+}$ to $\mathrm{Fe}^{3+}$ cations. A colour change in red ochre was unlikely to happen as the Fe cations are already in their highest oxidation state $(+3)$.

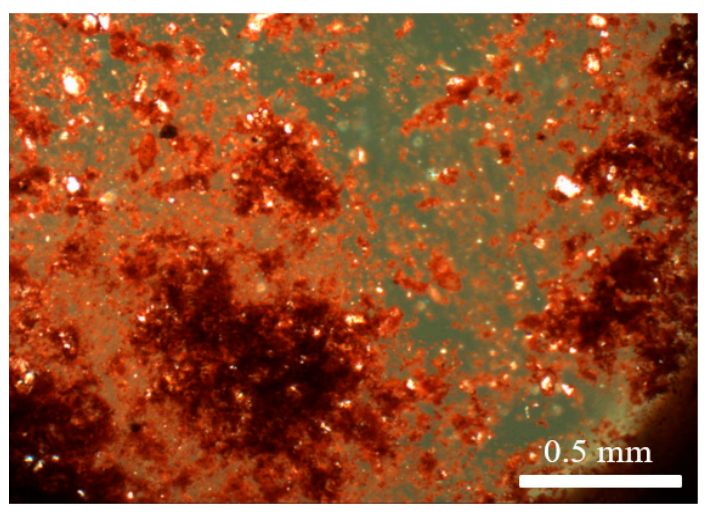

(a)

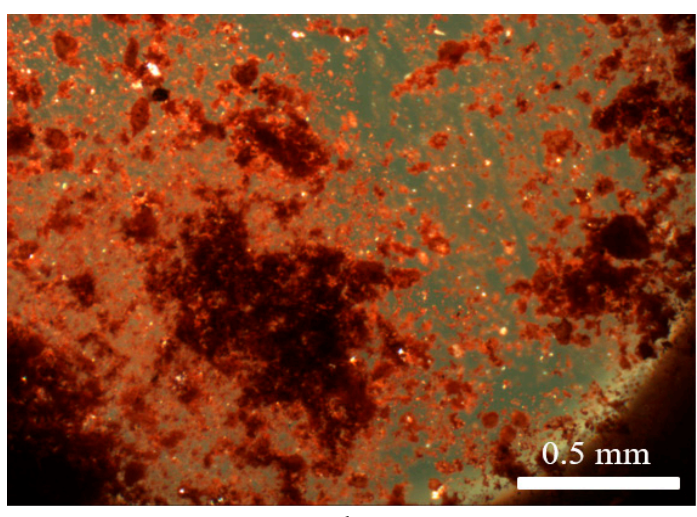

(b)

Figure 1. (a) Venetian red ochre before heating; and (b) Venetian red ochre after heat treatment at a maximum temperature of $580^{\circ} \mathrm{C}$.

The solubility screen served two functions: (i) to check whether any impurity or side product was soluble in any of the solvents and thus, whether it could be extracted; and (ii) whether the crystallites of the pigment underwent any structural changes. Predictably, the pigment itself did not dissolve despite vigorous stirring and heating in different solvents and solvent mixtures. This was confirmed by analysing the solutions obtained following filtration of the suspensions, by UV-Vis spectroscopy. The absence of absorption peaks corresponding to $\mathrm{Fe}^{3+}$ is a strong testimony to the pigment's insolubility. The undissolved pigment was analysed using FT-IR spectroscopy, and the spectra did not show any significant changes compared to the initial pigment.

The undissolved pigment was analysed via hot stage microscopy at different temperatures. The larger crystallites observed in the mixtures (vide supra) were still present after the solubility test, confirming that they were insoluble in the solvents and solvent mixtures used. The temperature at which these species lost transparency was different to that at which the unaltered pigment showed the same behaviour (Table 1). This also varied depending on the solvent, indicating that, although the pigment was insoluble, the respective solvent had a definite impact on the solid state properties of the pigment (Figure 2). This was likely due to the adsorption of solvent molecules onto or into the constituents of the pigment. The nature of the solvent, and the extent of adsorption, affected the temperature at which solvent molecules were lost upon heating.

Table 1. Temperature range at which crystals in Venetian red ochre lost transparency in each of the solvents or solvent mixtures.

\begin{tabular}{cc}
\hline Solvent & Temperature Range $/{ }^{\circ} \mathbf{C}$ \\
\hline Water & $130-145$ \\
Ethanol & $125-135$ \\
Methanol & $125-140$ \\
Acetone & $115-145$ \\
Dimethyl sulfoxide & $120-130$ \\
1:1 ratio of dimethyl sulfoxide and water & $125-145$ \\
1:1 ratio of ethanol and water & $120-140$ \\
1:1 ratio of acetone and water & $125-140$ \\
1:1 ratio of methanol and water & $135-145$ \\
\hline
\end{tabular}




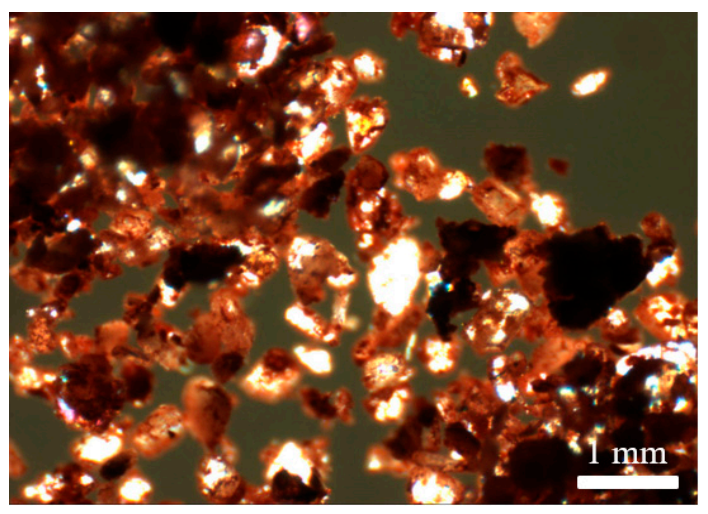

(a)

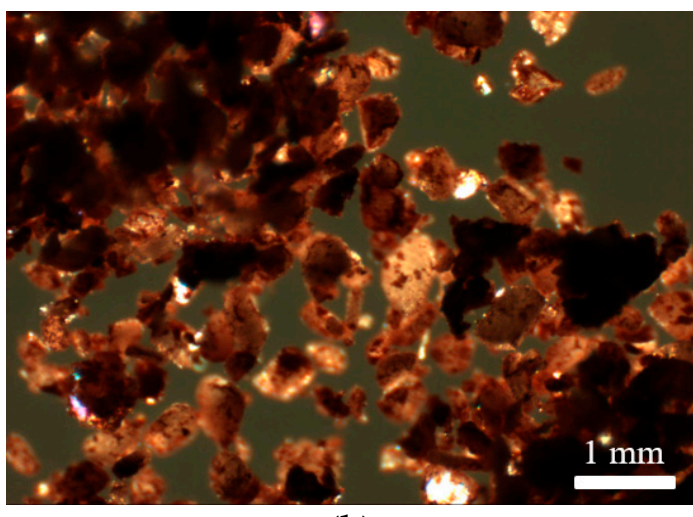

(b)

Figure 2. Venetian red ochre after suspension in a 1:1 mixture of water and methanol: (a) before heating; and (b) after heat treatment at a maximum temperature of $580{ }^{\circ} \mathrm{C}$.

Polymorph screening tests carried out on terra verde showed similar results. The temperature ranges in which loss of transparency of crystallites or change of colour was observed differed according to the solvent used. Figure 3 shows the pigment before and after heat treatment when suspended in DMSO/water 1:1 $(v / v)$.

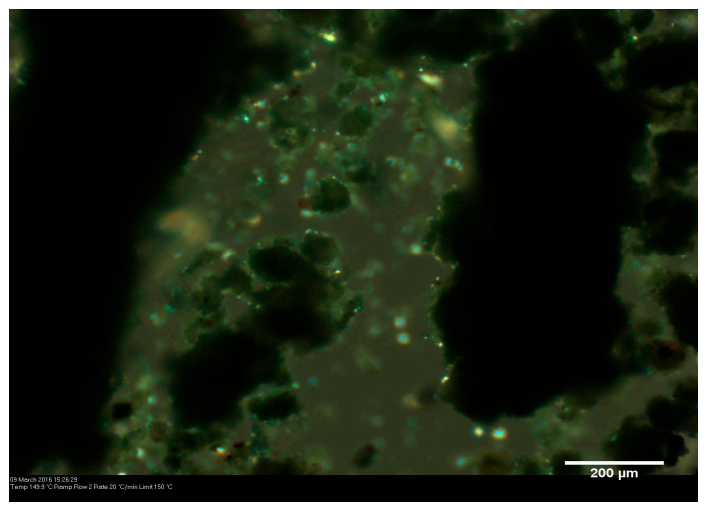

(a)

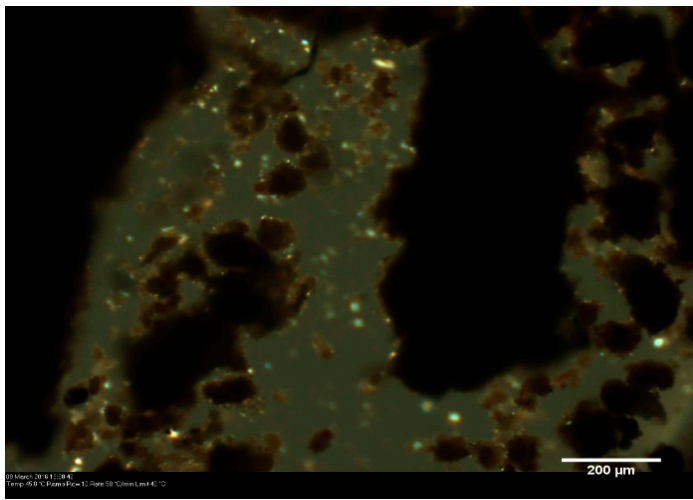

(b)

Figure 3. A sample of Verona terra verde from the polymorph screening in DMSO/water 1:1 (v/v): (a) before heating; and (b) after heat treatment at temperatures above $500{ }^{\circ} \mathrm{C}$.

Similar colour changes were also observed in red ochres, especially when there was still a significant amount of goethite in the actual pigment. The transformation of yellow ochre into red ochre was achieved by gradually heating lemon ochre (mainly goethite) to higher temperatures in order to form an increasing proportion of red ochre (mainly hematite).

Hot stage microscopy enabled observation of the visual changes ochres underwent with temperature (Figure 4), whereas variable temperature powder X-ray diffraction was instrumental in the determination of accompanying crystalline phase changes with temperature, notably the change from yellow to red ochre (Figure 5). 


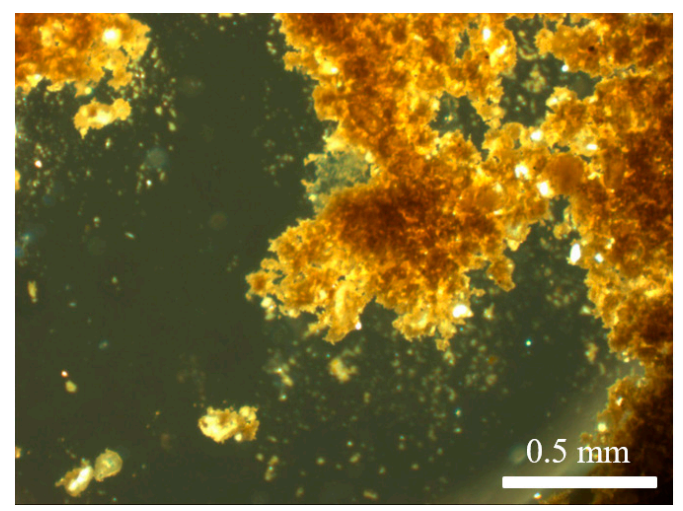

(a)

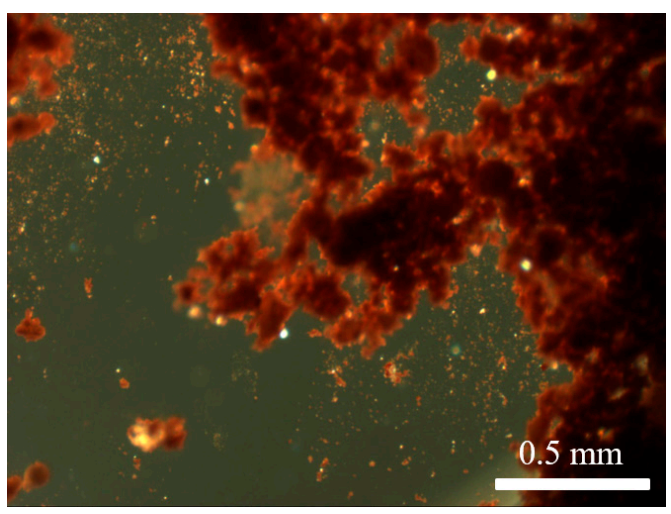

(b)

Figure 4. Microscope images of lemon ochre: unaltered (a); and after heating (b).

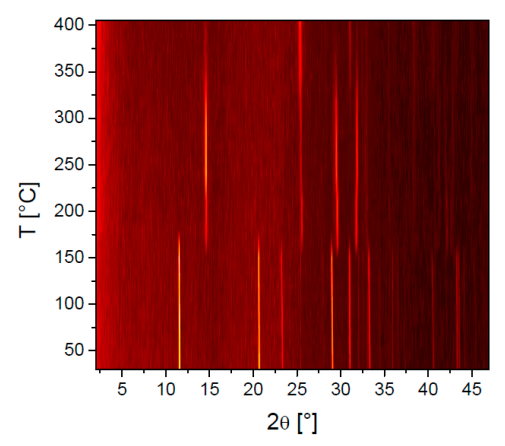

(a)

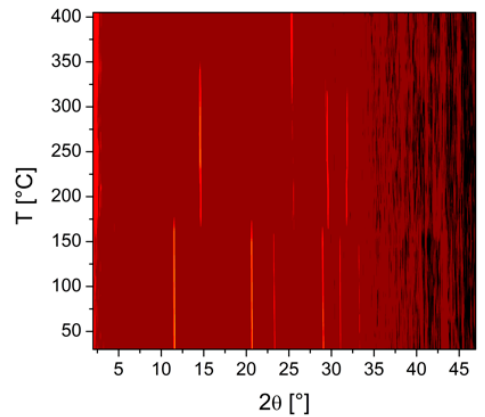

(b)

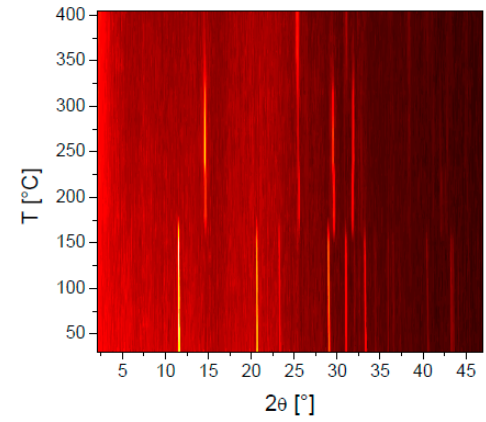

(c)

Figure 5. Variable temperature powder X-ray diffraction plots showing clear phase changes of: Venetian red ochre (a); Italian yellow earth (b); and lemon ochre (c).

\subsection{Characterisation of Venetian Red Ochre and Comparison with Verona Terra Verde}

Examination of Venetian red ochre under the microscope showed that it consisted mainly of microcrystals, which could not be visually identified as definite crystallites of hematite and goethite by their habits alone. Hematite crystals are expected to have a characteristic disc shaped morphology, whereas goethite crystallises in rods [14]. A small percentage of larger crystallites was present in the bulk. These colourless species were thought to be gypsum crystals, which was abundant in Venetian red ochre [14].

X-ray fluorescence spectroscopy showed the presence of 27 elements in Venetian red ochre (Figure 6). The most abundant element recorded was sulphur, followed by calcium, iron, magnesium and silicon.

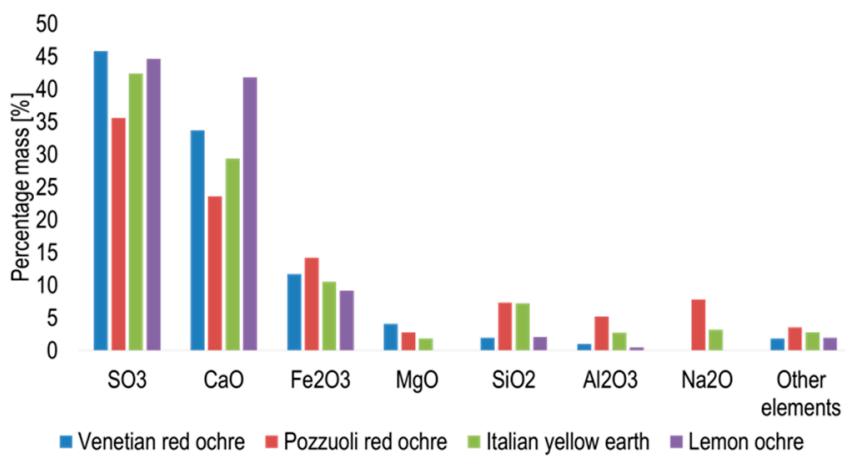

Figure 6. Graph showing the percentage mass of element abundant oxides in the ochres obtained via XRF. 
The results obtained by powder X-ray diffraction confirm the presence of hematite and goethite in the Venetian red ochre. Quantitative Rietveld refinement of the powder pattern at $30{ }^{\circ} \mathrm{C}$ revealed that the pigment consisted of $85.06 \%$ goethite and $14.94 \%$ hematite. Sequential quantitative Rietveld refinement of the $\mathrm{X}$-ray data for all four pigments enabled determination of the variation in percentage composition with temperature. Figure 7 summarises these variations for hematite and goethite. One very interesting observation was the non-linear change of percentages. Whilst all of the starting material first showed a steady increase of hematite, at temperatures around $165^{\circ}$, the amount of hematite increased rapidly, before decreasing again at temperatures $>300{ }^{\circ} \mathrm{C}$. A possible explanation for this anomaly was the interaction with the crystal water included in the solid-state structure. Hematite was mostly formed from goethite because of the simple condensation step needed to basically transform the $\mathrm{OH}$ moiety into $\mathrm{O}$. However, this crystal water could easily remain trapped in the solid and then catalyse hydrolysis of the oxide back to the hydroxide.

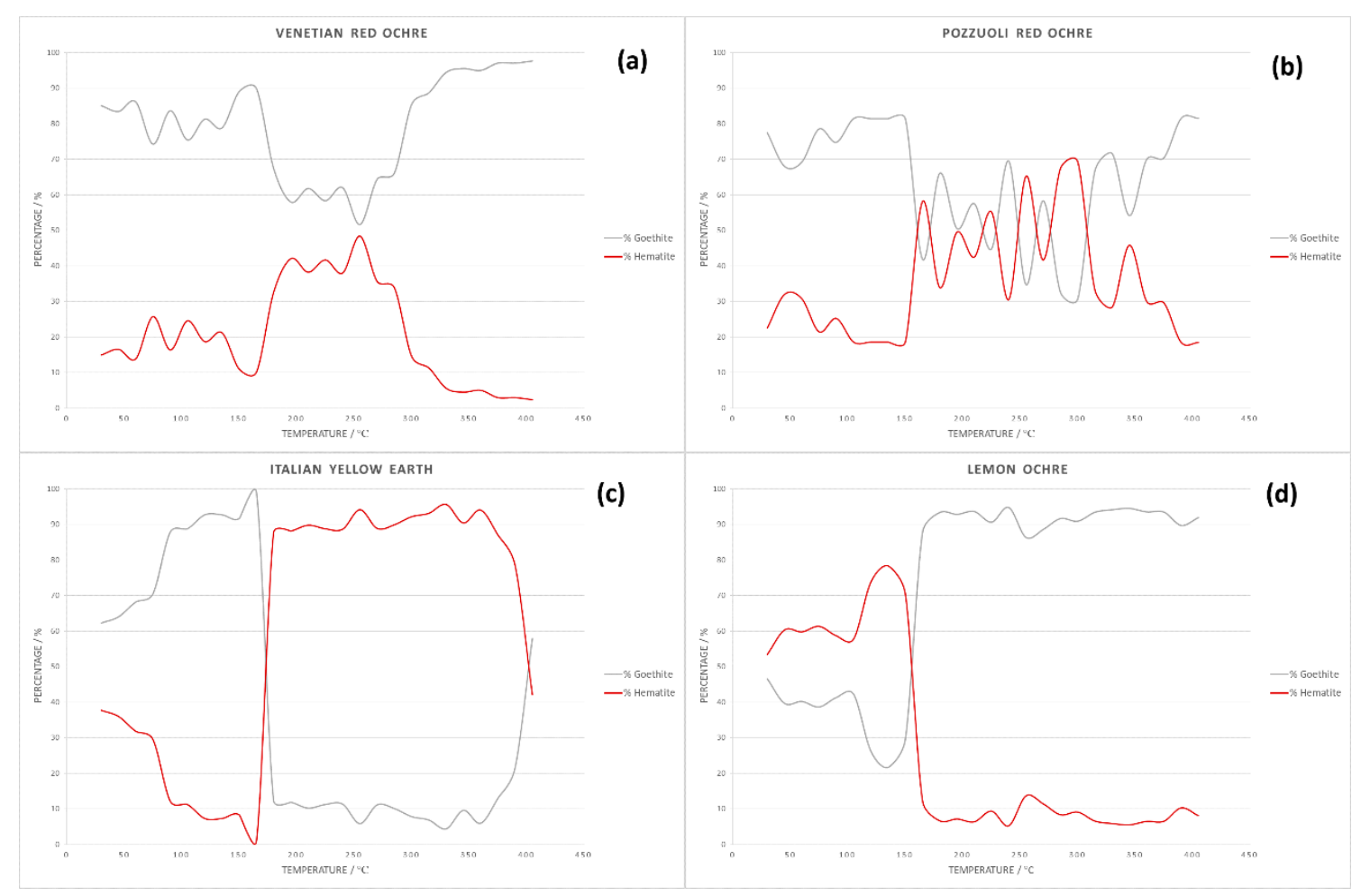

Figure 7. Graphs showing change in pigment composition with temperature for: (a) Venetian red ochre; (b) Pozzuoli red ochre; (c) Italian yellow earth; and (d) lemon ochre.

X-ray fluorescence was carried out in the same manner on Verona terra verde to determine the presence and proportion of various elements. Table 2 lists the main oxides of interest that are generally present in the pigment according to Dooley's empirical formula for terra verde: $\left(\mathrm{K}_{0.2} \mathrm{Na}_{1} \mathrm{Ca}_{4} \mathrm{Fe}_{2.6} \mathrm{Mg}_{0.5} \mathrm{Ti}_{0.2} \mathrm{Si}_{6} \mathrm{Al}_{4} \mathrm{O}_{23} \times 2 \mathrm{H}_{2} \mathrm{O}\right)$ [15].

These oxides made up $72.9 \%$ of the total oxide composition, with $25.8 \%$ being $\mathrm{SO}_{3}$ probably due to mineral sulphate impurities. The remaining $1.3 \%$ of oxides consisted of numerous trace impurities, and, as predictable for naturally-occurring compounds, none exceeded $1 \%$.

Fitting these data into Dooley's empirical formula for terra verde resulted in the following formula with a molecular weight of $1037 \mathrm{~g} \mathrm{~mol}^{-1}$ [15]: $\mathrm{K}_{0.2} \mathrm{Na}_{1} \mathrm{Ca}_{4} \mathrm{Fe}_{2.6} \mathrm{Mg}_{0.5} \mathrm{Ti}_{0.2} \mathrm{Si}_{6} \mathrm{Al}_{4} \mathrm{O}_{23} \cdot 2 \mathrm{H}_{2} \mathrm{O}$.

The XRF data showed that, predictably, the main components of the minerals were silicates and aluminates. The presence of high concentrations of calcium may not only be due to the calcium in the counter ion layer but also due to the presence of other minerals, such as montmorillonite, calcite and saponite, present due to the impurities collected during mining [16]. 
Table 2. Percentage concentration of oxides present in Verona terra verde used.

\begin{tabular}{cc}
\hline Detected Compound & Concentration, $\%$ \\
\hline Potassium Oxide & 0.875 \\
Sodium Oxide & 5.02 \\
Calcium Oxide & 24.6 \\
Iron (III) Oxide & 5.54 \\
Aluminium Oxide & 8.13 \\
Magnesium Oxide & 2.3 \\
Titanium Oxide & 0.658 \\
Silicon Oxide & 25.8 \\
\hline
\end{tabular}

\section{Conclusions}

This study presented surprising evidence of the impact that different solvents have on insoluble Venetian red ochre and terra verde upon heating. Neither the colouring agents nor the impurities were soluble in the solvents and solvent mixtures used in this study, since larger crystallites of the impurities were still observed in the undissolved pigment. However, these solvents brought about some changes in the undissolved pigment since the temperature at which the crystallites lost transparency was different to that at which the unaltered pigment showed the same behaviour. During this study, Venetian red ochre was characterised using the aforementioned techniques, the results of which all correlate with each other and confirm findings in the literature. Venetian red ochre consisted of a microcrystalline pigment, and larger crystallites thought to be gypsum, a non-ferric mineral. The most abundant compound in the pigment was gypsum, which was congruent with the results of multi-elemental analysis showing sulphur and calcium as the most abundant elements. Iron was found to be the third most abundant element in the pigment, forming part of the colouring agents, hematite and goethite. This pigment also contained alumosilicates, confirmed by the presence of silicon and aluminium, the nature of which has not yet been identified. Venetian red ochre retained its vibrant red colour upon heating. Some of the large crystallites found within the pigment lost transparency upon heating, which was attributable to a phase change.

Author Contributions: Conceptualisation, R.S. and L.V.-Z.; methodology, U.B. and L.V.-Z.; software, L.V.-Z.; validation, L.V.-Z., U.B., D.M. and T.R.; formal analysis, R.S., M.C. and D.M.; investigation, M.C. and D.M.; resources, L.V.-Z. and N.S.; data curation, M.C., D.M. and T.R.; Writing-Original Draft preparation, U.B.; Writing-Review and Editing, L.V.-Z.; visualisation, R.S. and T.R.; supervision, U.B. and L.V.-Z.; and project administration, L.V.-Z.

Funding: This research received no external funding.

Conflicts of Interest: The authors declare no conflict of interest.

\section{References}

1. Cornell, R.M.; Schwertmann, U. The Iron Oxides: Structure, Properties, Reactions, Occurrences and Uses; WILEY-VCH Verlag GmbH \& Co. KGaA: Weinheim, Germany, 2006.

2. Bonneau, A.; Pearce, D.G.; Pollard, A.M. A multi-technique characterization and provenance study of the pigments used in San rock art, South Africa. J. Archaeol. Sci. 2012, 39, 287-294. [CrossRef]

3. Román, R.S.; Bañón, C.B.; Landete Ruiz, M.D. Analysis of the red ochre of the El Mirón burial (Ramales de la Victoria, Cantabria, Spain). J. Archaeol. Sci. 2015, 60, 84-98. [CrossRef]

4. Toschi, F.; Paladini, A.; Colosi, F.; Cafarelli, P.; Valentini, V.; Falconieri, M.; Gagliardi, S.; Santoro, P. A multi-technique approach for the characterization of Roman mural paintings. Appl. Surf. Sci. 2013, 284, 291-296. [CrossRef]

5. Grissom, C.A. Green Earth. In Artists' Pigments: A Handbook of their History and Characteristics; Feller, R.L., Ed.; Archetype Publications: London, UK, 2012; Volume 1, pp. 141-168.

6. Granger, F. Vitruvius on Architecture Book VII; Harvard University Press: Cambridge, UK, 1970.

7. Piovesan, R.; Siddall, R.; Mazzoli, C.; Nodari, L. The Temple of Venus (Pompeii): A study of the pigments and painting techniques. J. Archaeol. Sci. 2011, 38, 2633-2643. [CrossRef] 
8. Thompson, D.V. The Practice of Tempera Paintings; Dover Publications Inc.: New York, NY, USA, 1962.

9. Laurie, A.P. The Painters' Methods and Materials; Dover Publications Inc.: New York, NY, USA, 1967.

10. Elias, M.; Chartier, C.; Prévot, G.; Garay, H.; Vignaud, C. The Colour of Ochres Explained by Their Composition. Mater. Sci. Eng. B 2006, 127, 70-80. [CrossRef]

11. Jercher, M.; Pring, A.; Jones, P.G.; Raven, M.D. Rietveld X-Ray Diffraction and X-Ray Fluorescence Analysis of Australian Aboriginal Ochres. Archaeometry 1998, 40, 383-401. [CrossRef]

12. Coelho, A. TOPAS and TOPAS-Academic: An optimization program integrating computer algebra and crystallographic objects written in C++. J. Appl. Crystallogr. 2018, 51, 210-218. [CrossRef]

13. Micallef, D.; Spiteri, R.; Baisch, U.; Vella-Zarb, L. Terra Verde: Overcoming the Problem of Transparency by Crystal Engineering. J. Cult. Herit. 2019, in press. [CrossRef]

14. Welton, J.E. SEM Petrology Atlas; The American Association of Petroleum Geologists: Tulsa, OK, USA, 2003; Volume 4.

15. Dooley, J.H. Glauconite. In Industrial Minerals and Rocks: Commodities, Markets, and Uses; Kogel, J.E., Trivedi, N.C., Barker, J.M., Eds.; Society for Mining, Metallurgy, and Exploration, Inc.: Littleton, CO, USA, 2006; pp. 495-506.

16. Ospitali, F.; Bersani, D.; Di Lonardo, G.; Lottici, P.P. 'Green earths': Vibrational and elemental characterization of glauconites, celadonites and historical pigments. J. Raman Spectrosc. 2008, 39, 1066-1073. [CrossRef]

(c) 2019 by the authors. Licensee MDPI, Basel, Switzerland. This article is an open access article distributed under the terms and conditions of the Creative Commons Attribution (CC BY) license (http://creativecommons.org/licenses/by/4.0/). 